\title{
Review on Procedures and Utilization of Artificial Insemination Technologies in Nekemte Semen and Liquid Nitrogen Production and Distribution Centre, Western Oromia, Ethiopia
}

\author{
Aklilu Biru ${ }^{1}$ Zelalem Abera' ${ }^{2 *}$, Misgana Duguma² and Ayantu Hundera ${ }^{3}$ \\ ${ }^{1}$ Nekemte Semen and Liquid Nitrogen Production and Distribution Center, Ethiopia \\ ${ }^{2}$ Wollega University, College of Medical and Health Sciences, Ethiopia \\ ${ }^{3}$ East Wollega Livestock and Fisheries Development and Resource office, Ethiopia
}

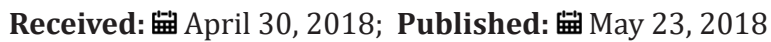

*Corresponding author: Zelalem Abera, Department of Veterinary Clinical Science and Laboratory Technology; School of Veterinary Medicine, Wollega University, Nekemte, Ethiopia

\begin{abstract}
It is known that long time before artificial insemination (AI) technology had only a single institution nationally i.e. National Artificial Insemination Center (NAIC) and which is found in Addis Ababa City, Kality area that is serving the community at national level. But now the government has given great emphasis establishing other four semen and liquid nitrogen production and distribution centers in four regional states. From these four AI technologies centers, one of them is instituted in Nekemte town, western Oromia, Ethiopia. This manual was conducted on procedures and utilization of artificial insemination (AI) technologies in Nekemte semen and liquid nitrogen and production and distribution centre, to determine how this technology is performed and to identify and evaluate the challenges and opportunities to characterize this technology. This manual was conducted to assess problems and constraints associated with the AI technologies, its adoption, utilizations and public awareness in the center and the community in the area. So, this manual indicates the procedures of this technology starting from the beginning of the selection of sound semen producing bulls up to the delivery of AI bred calves. During conducting this manual, it has been noted that after selection of bulls for breeding and up to the production of semen containing mini straws, it is passed through high complicated and tedious laboratory procedures which requires high techniques and efforts in addition to liquid nitrogen production. Therefore, the community should be aware of about this technology and use it properly for basic change.
\end{abstract}

Keywords: Artificial Insemination, Awareness, Challenges, Community, Nekemte, Opportunities; Semen; Domestic Demand; Livestock Sector; Hybrid Female Cattle

\section{Introduction}

Ethiopia has the largest livestock population in Africa, estimated at 45,054,969 cattle, 20,562,832 sheep, 20,191,099 goats and 2.4 million camels [1]. Recent figures indicate that the livestock sector contributes about $12-16 \%$ of national GDP, 30$35 \%$ of agricultural GDP [2], 15\% of export earnings and 30\% of agricultural employment. Livestock contributes to the livelihoods of $60-70 \%$ of the population [3]. The livestock sector in general and the dairy industry in particular do not provide the expected contribution to the national income despite their large numbers

due to several factors. The development of the dairy sector in the country is hindered by a number of technical, institutional and socio-economic constraints. The growth in milk production has been slow and the annual milk production is estimated to be $1,089,488,251$ liters [2] which doesn't meet even the domestic demand for dairy products. As a result, the country imports large volumes of dairy products per annum to meet the domestic demand. In 2005, for instance, the country imported 457,260 kg of milk (liquid and powder) which is equivalent to 3,026,724 Birr [2]. 
The dairy sector is dominated by smallholder farmers who account for about $85 \%$ of the population and are responsible for $98 \%$ of the milk production [2]. Rapidly increasing population size with a growing urbanization is resulting in a growing demand for dairy products in Ethiopia. Dairy development can lead to growth in rural areas by increasing farm income and employment opportunities. Besides low milk production levels, milk collection, processing and marketing are not well developed in the country. A comprehensive chain approach aimed at sustainable development of the dairy sector is lacking.

To build a successful and sustainable dairy industry, all possible entry points for intervention across the milk value chain have to be identified; from cow to consumer. Different parts of the value chain need different kinds of support and intervention where the situation of course requires various case to case interventions. Several entry points could be identified across the dairy value chain with varied degree of resource requirement and levels of competition. Raising the genetic potential of local breeds for significantly higher milk production through crossbreeding with exotic dairy breeds using $\mathrm{AI}$ and synchronization in the MRS, and in the dairy sheds and periurban areas in the MRD [4]. Agriculture (mainly crop and livestock production) is the mainstay of the Ethiopian economy employing approximately $85 \%$ of the total population. Livestock production accounts for approximately $30 \%$ of the total agricultural GDP and $16 \%$ of national foreign currency earnings [5]. The total cattle population for the rural sedentary areas of Ethiopia is estimated at 43.12 million, of which $55.41 \%$ are females. Out of the total female cattle population, only151, $344(0.35 \%)$ and 19,263 (0.04\%) heads are hybrid and exotic breeds, respectively. With an average lactation length of 6 months and an average daily milk production of 1.44 liters per cow, the total milk produced during the year 2006/07 was recorded to be 2.634 billion liters [6]. This suggests that the total number of both exotic and hybrid female cattle produced through the crossbreeding work for more than four decades in the country is quite insignificant indicating unsuccessful crossbreeding through AI.

Artificial insemination (AI) has been defined as a process by which sperm is collected from the male, processed, stored, and artificially introduced into the female reproductive tract for the purpose of conception [7]. Semen is collected from the bull, deep-frozen and stored in a container with Liquid Nitrogen at a temperature of minus 196 degrees Centigrade and made for use. Artificial insemination has become one of the most important techniques ever devised for the genetic improvement of farm animals. It has been widely used for breeding dairy cattle as the most valuable management practice available to the cattle producer and has made bulls of high genetic merit available to all $[7,8]$. In Ethiopia, AI was introduced in 1938 in Asmara (the current capital city of Eritrea), the then part of Ethiopia, which was interrupted due to the 2nd World War and restarted in 1952 [9]. It was again discontinued due to unaffordable expenses of importing semen, liquid nitrogen and other related inputs requirement. In 1967, an independent service was started in the then Arsi Region, Chilalo Awraja under the Swedish International Development Agency (Sida). The technology of AI for cattle has been introduced at the farm level in the country over 35 years ago as a tool for genetic improvement [10]. The present National Artificial Insemination Center (NAIC) was established in 1984 to coordinate the overall AI operation at national level [11]. The efficiency of the service in the country, however, has remained at a very low level due to infrastructure, managerial, and financial constraints, as well as poor heat detection, improper timing of insemination and embryonic death [12].

A cattle breeding is mostly uncontrolled in Ethiopia making genetic improvement difficult and an appropriate bull selection criteria have not yet been established, applied and controlled [13]. Although artificial insemination, the most commonly used and valuable biotechnology [7] has been in operation in Ethiopia for over 30 years, the efficiency and impact of the operation has not been well-documented [14]. Reproductive problems related to crossbreed dairy cows under farmers' conditions are immense [15]. It is widely believed that the AI service in the country has not been successful to improve reproductive performance of dairy industry [16]. From the previous little studies, it has been found that AI service is weak and even declining due to inconsistent service in the smallholder livestock production systems of the Ethiopian highlands [17]. The problem is more aggravated by lack of recording scheme, wrong selection procedures, and poor management of AI bulls associated with poor motivations and skills of inseminators [11]. The Oromia regional state is also the largest region of the country and its agro-ecology and climatic conditions are suitable for cattle and other livestock productions and known by its large number of livestock; where cattle rearing technologies are applied. However, the challenges and constraints mentioned above always threaten the region in benefiting from these technologies. These AI technologies are now given a special focus from the Ethiopian government widely and the technology was newly established in four Regional States of Ethiopia; in which one of them was instituted in Nekemte town of East Wollega Zone; Oromia Regional States of Ethiopia.

However, this technology had been introduced to Ethiopia long years ago, the accommodation and utilization of this technology has not yet met the intended goal. Even though the government gave a good emphasis on the development of livestock sector with good attention to breed improvement through artificial insemination technologies, still it needs special community mobilization in using this technology. The Nekemte semen and liquid nitrogen production and distribution center instituted newly at Oromia Regional state is achieving its mission with its many internal and external challenges and with poor attention and understanding of the community at large. 
Therefore the objectives of this manual were:

To create public awareness on procedures, how to accommodate and utilize AI technologies and give the utmost attention to the AI operation at all levels. To characterize technologies of artificial insemination and utilization.

\section{Requirement on semen producing bulls}

Breeding soundness: Healthy, in a good state and complete. Bulls born of elite parents of proven record, Bulls with typical breed character, Bulls should be free from communicable diseases, Bulls should be physically sound: Hind legs should be without any abnormality (Sickle shaped bow or straight hocks).The neck, eyes, and shoulders should be normal. Reproductive soundness. Condition of testicles Presence: Size (length breath), Consistency: firm scrotal circumference (Figure 1). Breeding soundness exam is done by: Breeders and Veterinarians.

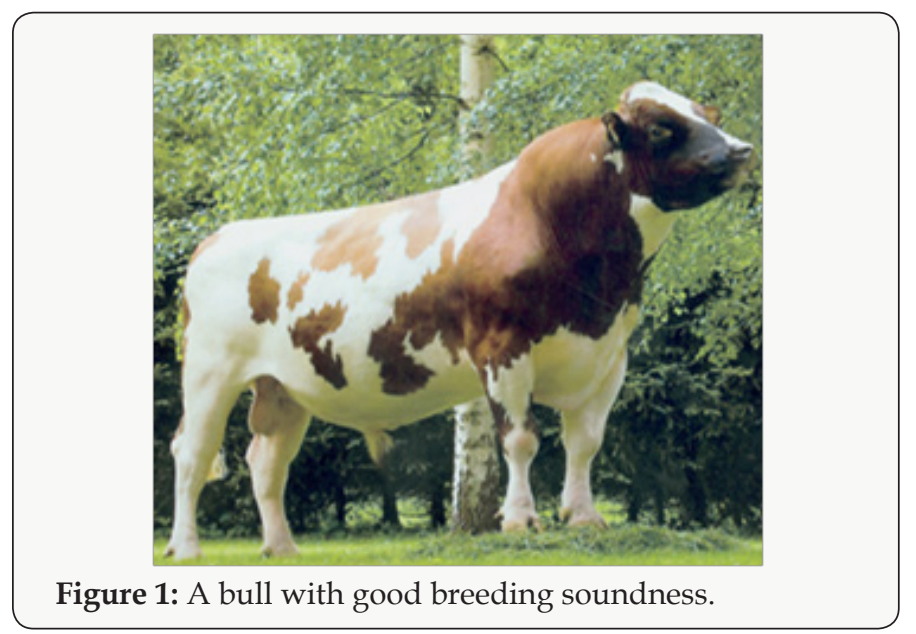

\section{Semen Producing Bulls}

Should be free from diseases of environmental and genetic origin and must be capable of producing large quantities of semen that is fertile after freezing and storage. Therefore, bulls selected for semen production from any source are subjected to veterinary investigation. The goal is to protect the health of the seminal donors and the herds in which the semen is used. A physical examination shall be conducted by accredited veterinarian to determine that the bulls do not display any clinical symptoms of diseases.

\section{Special Physical Examinations}

Genital organ: Testicle, Epididymis, Penis, prepuce and scrotal sac: Form and content any disease condition of skin, incomplete decent of testicle (cryptochidism). Atrophy or scrotal hernia (Figure 2 and Figure 3).

Step 1: Fertility Examination: The main objective of this examination is to eliminate infertile bulls and improve the genetic base for fertility with in breeds. Thus prior to the acceptance of bulls for semen collection: All bulls are subjected to various examinations on their genital system, All bulls are trained to use the AV, All bulls are checked for mating behavior and semen quality.
Step 2: Patterns of bull's sexual behavior. Different phases of bull's sexual behavior (Libido) should be observed through offering of a teaser: Male, Female or Dummy cow.

The sexual arousal or libido of a bull is expressed in the form of:

a) Courtship - seeking the love of sexual partner in the form of: Guarding, Flehmen reaction, Chin resting, Sniffing or Licking.

b) Erection of penis and penile Protrusion: Erection during seekingNo erection after mounting, Poor erection, Penis slack, Good erection, Penis stiff, Very good erection, Penis hard and straight.

c) Seeking for vulva (location): Quick, Medium or Low

d) Ejaculatory thrust: No thrust despite contact with AV, Weak and short body thrust, Strong deep, good thrust with lifting up of hind legs.

e) Ejaculation: Complete /partial in AV, Partial outside the $\mathrm{AV}$ or In prepuce

f) Dismounting: Normal or Deviation from normal

g) Refractoriness: unmanageable

All sexual patterns are separately evaluated to get a complete picture of the serving capacity of the bull. A simple score system from: 1 to 4 (poor-very good) is given. Intense Libido - reaction time up to 3minutes, Normal Libido - reaction time up 3 to 10 minutes, Poor Libido - reaction time over 10 minutes. In general follow the steps from bull preparation upto improved breeds (AI bred calves) listed in this manual (Figure 2).

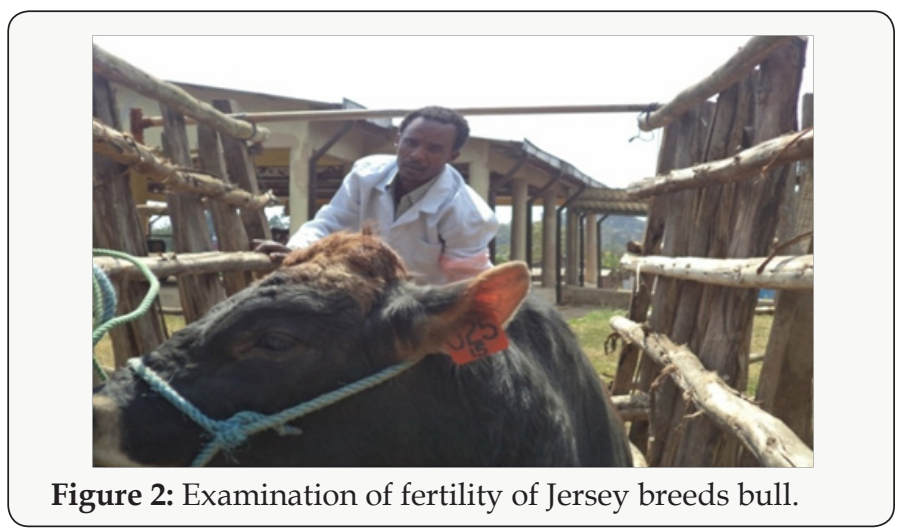

\section{Diagnostic Tests}

Tuberculosis and Bovine Brucellosis: Successful bulls shall be transported to AI center.

The main objective of this examination is to eliminate infertile bulls and improve the genetic base for fertility with in breeds.

Clinical Andrological Evaluation of the Bull: Epididymis: Size, Shape and Sensitivity; Prepuce is checked for: Inversion, Adhesion and Abnormalities. 
a) Penis: Developmental abnormalities, Injuries and Diseases Accessory sex glands: Ampula, Seminal vesicles and Prostate. Bulbourethral glands are palpated through rectum for a possible change in size, shape and consistency (Table 1) (Figures 3 \& 4). Semen Collection Process and hygienically prerequisite. The floor of the mounting area should be easy to clean and disinfect. Recommended materials are concert, brick, asphalt and rubber. A dusty floor must be avoided. Mount animals "teaser bull" must be kept clean in its hindquarters. Areas of contact by the erect penis or of general secretions up on the hair coat or skin of a mount shall be effectively and thoroughly disinfected between successively mounting bull.

Table 1: Bos Taurus and Cross bred bulls of scrotal circumference evaluation.

\begin{tabular}{|c|c|c|c|}
\hline \multirow{2}{*}{$\begin{array}{c}\text { Bull's Age in } \\
\text { (months) }\end{array}$} & \multicolumn{3}{|c|}{ Scrotal Circumference Evaluation } \\
\cline { 2 - 4 } & Very good & Good & Poor \\
\hline $12-14$ & 34 & $30-34$ & 30 \\
\hline $15-20$ & 36 & $31-36$ & 31 \\
\hline $21-30$ & 38 & $32-38$ & 32 \\
\hline 31 & 39 & $34-39$ & 34 \\
\hline
\end{tabular}

Figure 3: Holstein and Jersey breed bulls with good
scrotal circumferences.

Figure 3: Holstein and
scrotal circumferences.

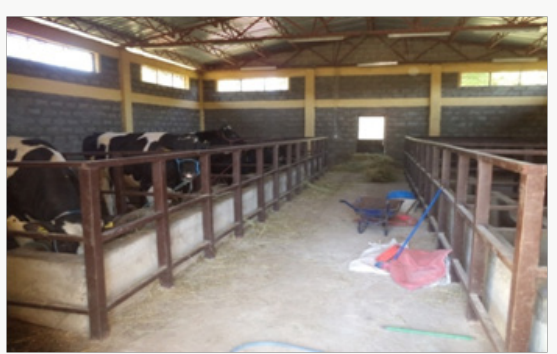

Figure 4: Nekemte semen and liquid nitrogen production and distribution center bull house.

Step 3: Bull preparation for Semen Collection

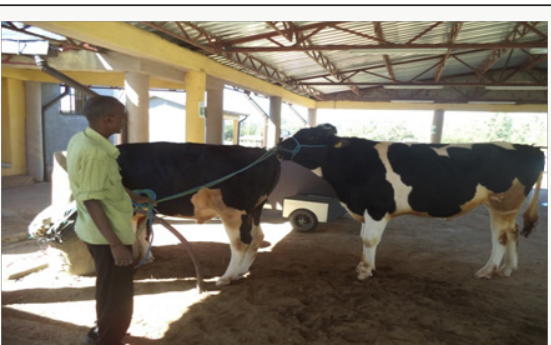

Figure 5: Sexual preparation of the bulls prior to semen collection.
Semen producing bulls are selected first and recreate for a given minutes and the hair around their prepuce are cutted using scissors and showered with clean water, soap and brush well and sexually prepared. Sexual preparation of the bull prior to semen collection will improve the quality of semen obtained. This will be done through false mounting and allowing the bull to watch other bulls mounting. The hand of the person collecting the semen must not come in contact with the bull's penis. Sanitation and the technical skill of both the semen collector and the handler of the bull are important (Figure 5).

\section{Step 4: Preparation of Artificial Vagina (AV)}

It is necessary to clean the artificial vagina completely before each collection. It should have been dismantled beforehand; its various parts washed, rinsed and dried, and kept protected from dust. The inside of the body of the device and cone is dipped in alcohol before reassembly. Once assembled it should be kept in a cupboard, which is regularly cleaned and disinfected. The AV is simple and simulates natural mating. It should provide the proper: temperature, pressure (controlled by water and air) and lubrication for ejaculation. The lubricant used is packed in tubes and should be sterile. The rod used to spread the lubricant must be sterile and should not be exposed to dust between successive collections. It is strongly recommended that the $\mathrm{AV}$ not be shaken after ejaculation, as otherwise lubricant and debris may pass down the cone to join the contents of the collecting tube. A new artificial vagina should be used for each mounting. The vagina should also be changed when the bull has inserted its penis without ejaculatin (Figure 6).

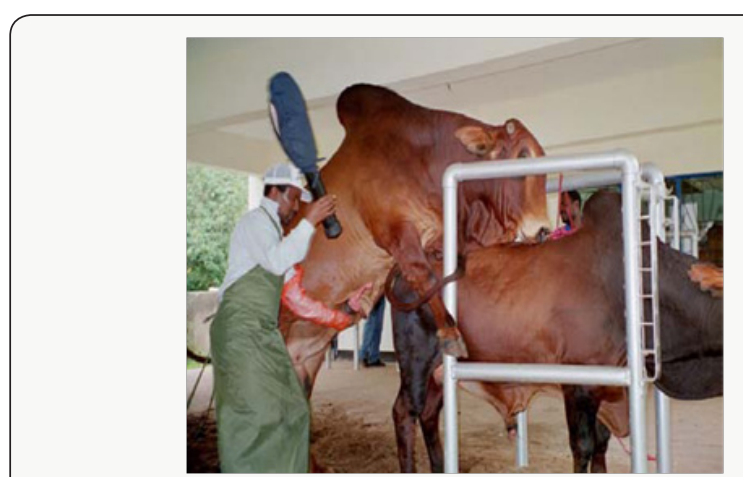

Figure 6: Semen collection process.

The collecting tube for semen must be sterile, and the recommended method of sterilization is heating in an oven at 180 oC for at least $30 \mathrm{~min}$. They should be sealed while waiting use, for example by a plug of sterile cotton wool or aluminum foil, and kept in a sterile box or cupboard until required. After collection, the tube should be left attached to the cone and within its sleeve until it has been removed from the collection room for transfer to the laboratory (Figure 7). When collecting semen, wear personal protective equipments (head caps, gown, boots and aprons) and the collector should be ready and handle the AV in right position and immediately the semen producing bull mounts on the teaser bull hce of he/she handle the prepuce of the not the penis and horizontally insert the penis into the AV (Figure 6). 


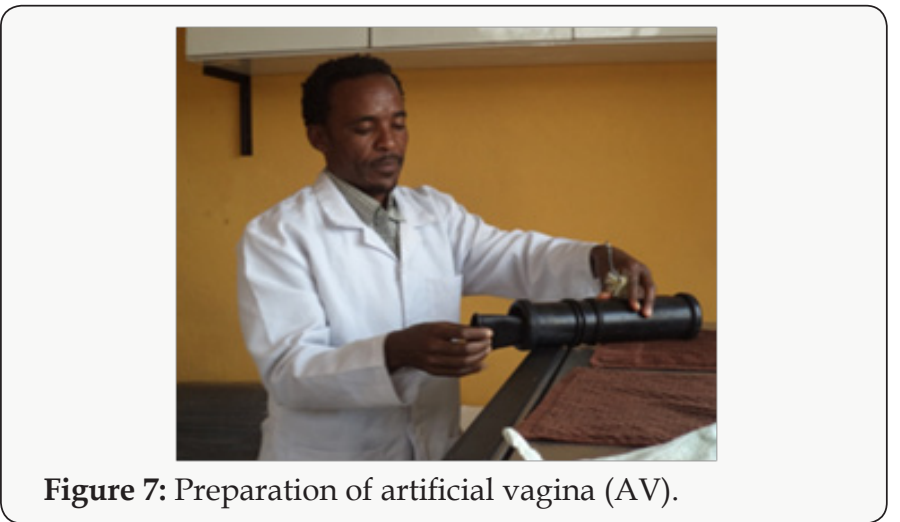

\section{Step 5: Semen Processing After Collection}

In case of semen processing, all operations should be carried out in an enclosed area, reserved exclusively for the purpose and accessible only to the technicians who work there. The building should be well lit, with walls and floors easy to clean and disinfect, and provided with one or more benches, which are also easy to clean and disinfect. It is advisable to have a service hatch through which the semen sample can be passed, in order to reduce to a minimum the movement of air (Figure 6 \& Figure 8).

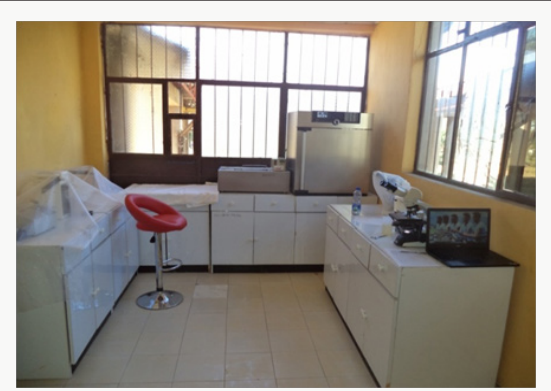

Figure 8: A clean semen processing room of Nekemte AI center.

\section{Step 6: Semen Evaluation}

Several tests have been carefully combined to select potentially fertile ejaculates for freezing. Semen evaluation is done for:

a) The determination of reproductive distrunce that has its origin in sperm cell and

b) The use of semen for artificial insemination-fertility diagnosis.

For a complete examination of fertility and evaluation of sperm producing bull, three collections at an interval of one week is performed. Appearance and volume, Density-Concentration, Individual and Mass activity

\section{a) $\mathrm{PH}$}

b) Abnormalities (morphological change)

In case of volume and appearance, the bull semen varies between ejaculates, bulls, breeds and ages. However, a bull with less than $2 \mathrm{ml}$ per ejaculate volume is not acceptable. Normal bull semen varies in color. Feed and contaminants may change the color of semen. In case of contamination, it will not be accepted for further processing. In general, normal bull semen varies in appearance and range from milky, yellowish to creamy in color. The operations should be performed by personnel specifically allocated to the task. Once the semen has been found to meet the required quality standards it is diluted at $35-37 \mathrm{oC}$ as soon as possible. The temperature is maintained by a water bath both before and during dilution (Figure 8).

Since every insemination dose should contain at least 15-40 million sperm cells, the amount of extender added will depend on the quantity of sperm cells in the ejaculate. This is confirmed by photometer, readings (Figure 9).

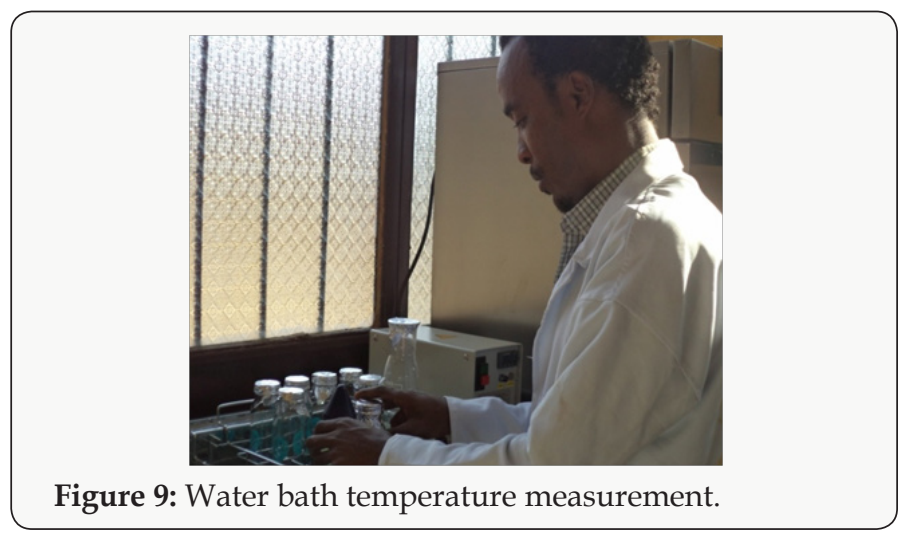

Step 7: Motility Evaluation

Mass activity is evaluated in drop of semen without cover slip under low magnification. A rapid wave motion with formation of eddies at the end of waves indicate a good quality semen. A simple score system from one to 4 (very good is used). Individual motility is evaluated in small drops of semen under cover slip at higher magnification. Only sperm cells moving in straight-line forward direction are included in the motility count. During evaluation, bull semen should have at least $70 \%$ motility at the time of collection and $40 \%$ after freezing to be acceptable for breeding purpose (Figure 10).

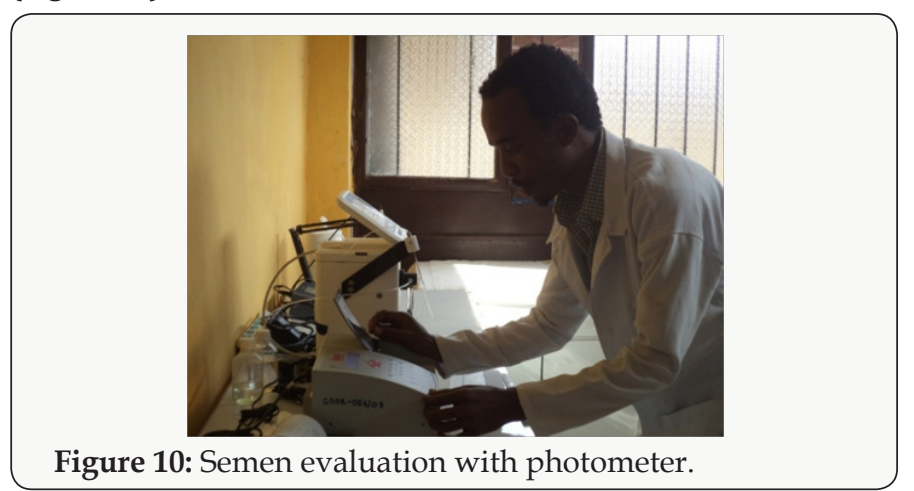

Step 8: Ph, Density and Cell Morphology Evaluation

Semen PH should range from 6.0 to 7.0. Semen with above PH is considered as inflammatory process in reproductive organs/low 
concentration. The density of semen is calculated with a calibrated automatic electronic photometer. It can also estimate visually. Very good thick, creamy or white, opaque and viscid, yellowish. Good Creamy white and opaque but less viscid. Fair -Milky in colour, more dilute, approaches translucency pours freely. Poor-watery, gray in colour, pours freely. The prevalence of abnormal sperm cells (Morphological defect and dead cells) is determined by examining the semen smears stained by: Wet smear method and EosinNigrosin staining method (Figure 11).

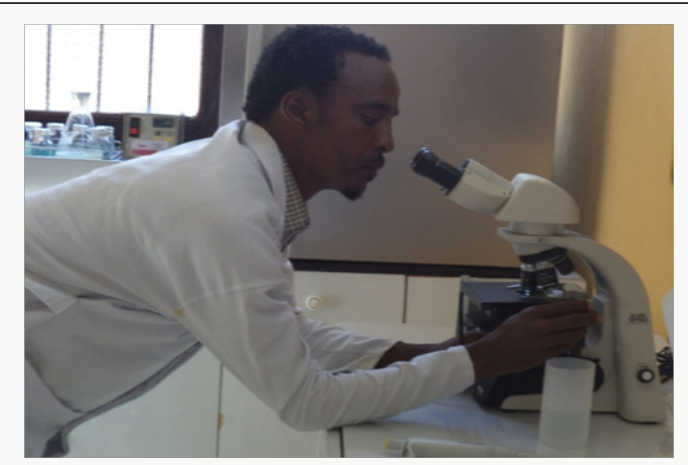

Figure 11: Mass and individual motility evaluation.

Eosin -Nigrosin staining method is used to count live and dead sperm cells:

i. From stock solution of Eosine 5\% and Nigrosine 10\%

ii. 3 drops and 5 drops respectively are mixed in a small glass test tube maintained in a water bath at $340 \mathrm{oC}$.

iii. Two (2) drops of mixed stain and a small drop of semen are taken on a pre- warmed slide and mixed gently

iv. Two smears are prepared and allowed to dry in the air.

v. Random fields (diagonally) are counted over the slide to obtain a representative figure.

vi. A maximum of 300 sperms are counted to find out the percentage of live sperm using the following formula:

vii. No of live sperm counted X $100=$ $\%$

viii. No of total sperm counted.

ix. The death percentage per slide should not exceed $30 \%$.

x. If part of the sperm is stained, such as the nucleus, it is counted as dead.

\section{Step 9: Printing Mini Straws Using AAN Automated Machine,}

\section{Domino}

At this step, mini straws are labeled with bull ID, batch number, date, breed, blood composition of the bull and name of the producing centre/station and printed with an automated computerized machine called domino (Figures 12 \& 13). The extended Semen is cooled to $4-5 \mathrm{oC}$ within one hour in the refrigerator. Afterwards, the cooled diluted semen would be brought to the cold cabinet at 4-5oC and the final dilution is performed. The extended semen is allowed to stand for several hours (3-6h) to allow the sperm to equilibrate to the cold. After equilibration the semen is packed in to the mini straw that is carefully marked with the station, bull ID, batch no, production year etc (Figure 14). At the time of filling and sealing, the straws should bear the same temperature as the semen 4-5oC the packed straws are arranged on the racks for freezing (Figure 14).

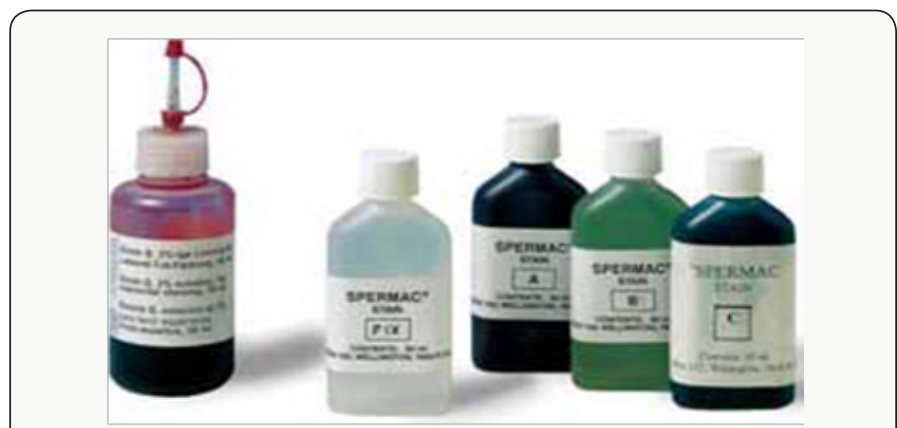

Figure 12: Stainning dyes.

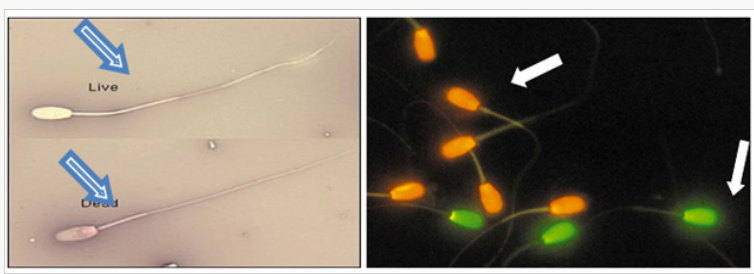

Figure 13: Live-Dead combination of fluorescent dyes such as sybr-14 which stains viable sperm green and propidium iodide which stains dead sperm red.

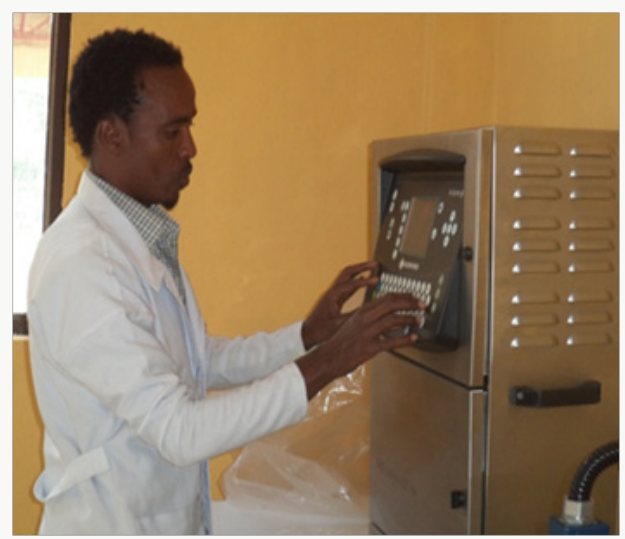

Figure 14: Printing of mini straws using a computerised machine, domino.

\section{Step 10: Slow and Controlled Freezing}

This is carried out by using programmable bio-freezer. Rate of freezing programme is fed and stored in the computerised programmable bio-freezer.

a) The transfer of racks with the packed straws from cold handling cabinet to bio-freezer should not exceed 2 minutes (Figure 15). 


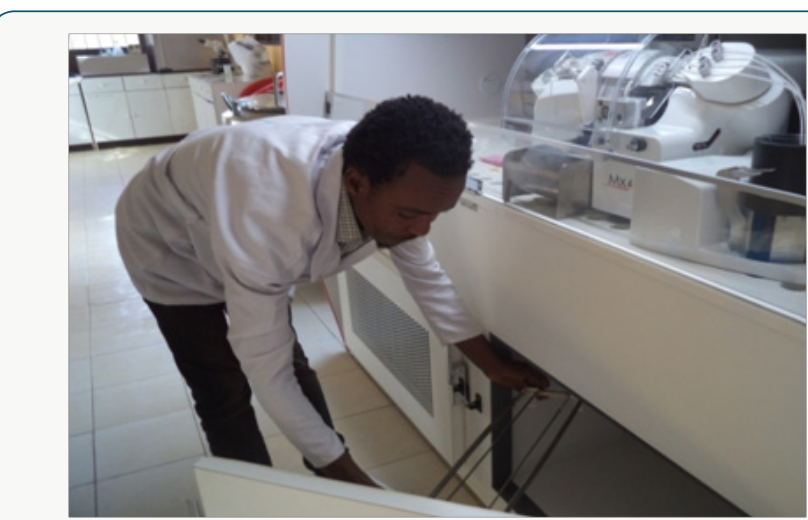

Figure 15: Equiliberation of packed straws after sealing over 3hour.

b) The transfer of to-1400 $\mathrm{C}$ freeze racks with the straws from bio-freezer to wide mouth liquid nitrogen container (should not exceed 10minutes (Figure 16). In the wide mouth container, the freeze straws are transferred in the pre-cooled goblets and are plunged directly in the liquid nitrogen.

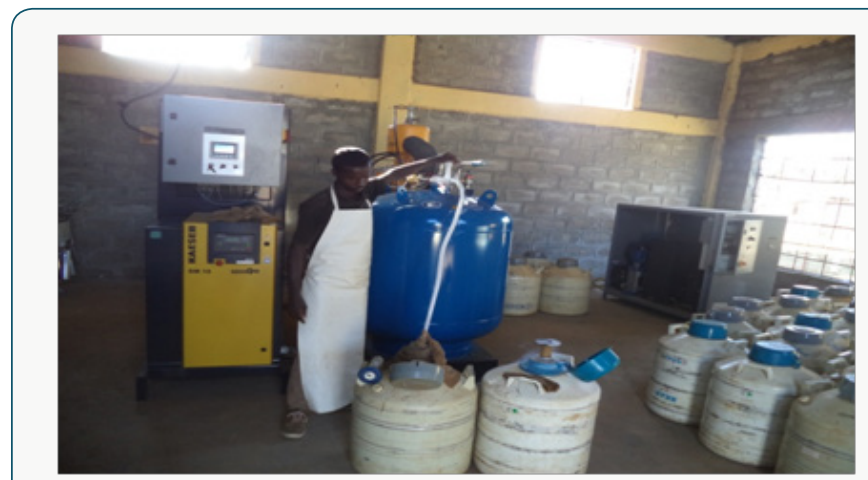

Figure 16: Liquid nitrogen production plant.

\section{Production of Liquid Nitrogen}

\section{Step 1- Compress the Air}

The ambient air consists of 21\% oxygen, 78\% Nitrogen and $1 \%$ other gasses (for example argon). Production almost nitrogen is therefore simply a matter of filtering the oxygen out of the compressed air. Ambient air enters the compressor. This is the unconditioned air that we all breathe from which we use subtract the nitrogen part and liquify it. The ambient air enters the compressor to be compressed to a higher pressure.

\section{Compressor Details}

The compressor should always be ON when the Cry generator is $\mathrm{ON}$. The pressure should be stable to have a continuous flow to the subsequent modules. The actual pressure can be read from the compressor control panel during operation. The compressor will provide the incoming pressure for the Dryer and the PSA modules.

\section{Step 1: Filter and Dry the air}

In this module condensed moisture, oil particles and dust in the air are removed by the water separator, filter elements and air.

\section{Step 2: Separate the Nitrogen}

The separation of Nitrogen from the incoming compressed air is accomplished by Pressure Swing Adsorber which consists of two oxygen adsorbed vessels.

\section{Separator details}

The see vessels are filled with carbon molecular sieves, which have the capacity of binding oxygen molecules. The residual water will also be removed. After adsorbing a certain amount of oxygen, the sieves are saturated and must be regerated. Therefore the adsorbed vessels are used alternatively. When one vessel is adsorbing oxygen, the other vessel is being regenerated. Regeneration is accomplished by de-pressurizing the vessel to the ambient pressure and flushing it with part of the purified Nitrogen, thus blowing of the oxygen.

\section{Step 1: Cool the Nitrogen to Liquid Nitrogen}

In the Cryogenertor gaseous Nitrogen coming from the PSA is liquefied. The cold for the liquefaction is generated by the Stirling cycle. This is basically the compression and expansion of the process gas Helium. Compression and expansion take place in two separate spaces. A water cooler and a regenerator thermally apart the warm compression space and the cold expansion space. The water cooler removes the heat generated during compression.

\section{Cry Generator Details}

The expansion of the process gas cools the cry generator's condenser head. The Nitrogen flows along the condensor head, and is thus liquiefied. Non condenable gases (e.g. $\mathrm{He} \mathrm{H} 2 \mathrm{Ne}$ ) are removed the condenser head.

\section{Step 1: Store the Liquid Nitrogen}

The vessel stores the Liquid Nitrogen coming from the Cryognerator. Use the tap mounted on the vessel to retrieve the desired quantity of Liquid Nitrogen.

\section{Storage details}

The vessel is vacuum isolated to ensure minimum heat loss.

\section{The Machine Parts}

The sterling cryogenic system is used to liquify nitrogen gas to liquid nitrogen. The cryogenic system contains modules with Stirling Process Cry generator (SPC) as the heart of your cooling system (Figure 15). The sterling Cryogenic system can consist of frames that contain several modules (Figure 16). There is also system where the modules are not placed in a frame. These modules are placed stand-alone in the room. Figure 17 Equilibrated semen for 9 minute at -130 to -140 OC in wide mouth tank. Before transferring the semen to the long-term storage the results of freezing is checked by thawing immediately after freezing (0h) one or two random sample straw at $35 \mathrm{oC}$ for 15 to 45 seconds in water bath. Any sample showing below $40 \%$ progressive motility is discarded from farther use (Figure 18). 


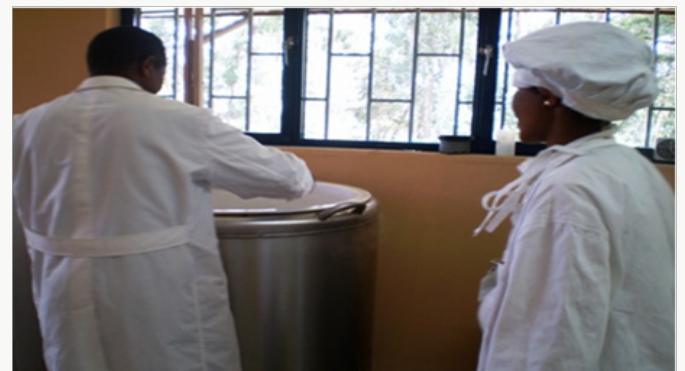

Figure 17: Equilibrated semen for 9 minute at -130 to $-1400 \mathrm{C}$ in wide mouth tank.

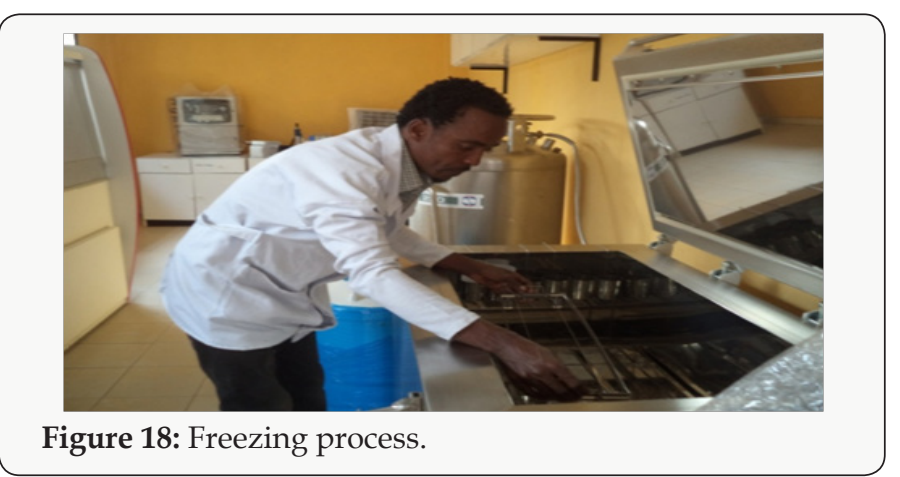

Step 1: Storage of Accepted Semen

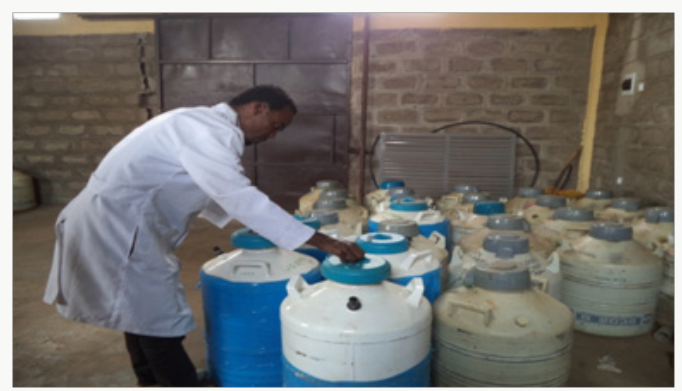

Figure 19: Storage of accepted semen in liquid nitrogen.

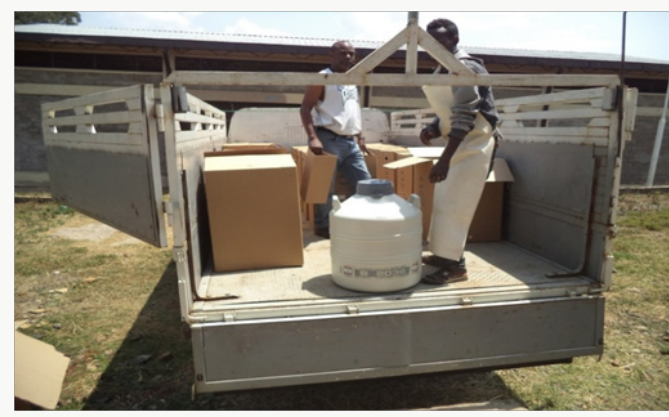

Figure 20: Dispatching of semen and liquid nitrogen from storage for farmers.

The accepted semen dose is kept in the liquid nitrogen container (bulk storage container) and store in a dried and well ventilated area and place on a board or cut off concrete to prevent corrosion to the bottom of tank and keep tank locked. Semen has been used successfully after almost 20 years of storage in liquid nitrogen. It is extremely important to monitor the nitrogen level. Loss of all liquid nitrogen results in damage to the sperm even though the semen may appear to be still frozen, the remaining straws are best examined and compared to properly stored straws of the same batch (Figures 16-21).

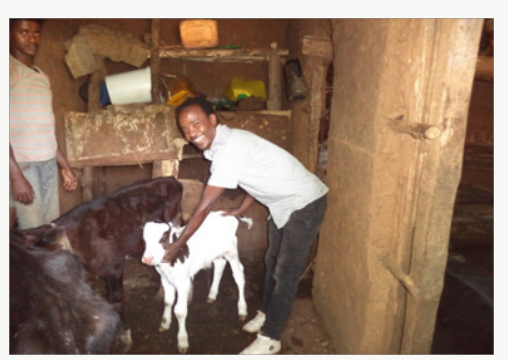

Figure 21: AI bred calves in Nekemte 03 kebele (Chelelek).

\section{Conclusion and Recommendations}

AI service in Ethiopia has been given little or no emphasis at the federal, regional or wereda levels during the before long time even though it is a widely practiced animal biotechnology all over the world. The most important constraints associated with AI service in Ethiopia include less structural linkage between AI Center and service giving units, absence of collaborations and regular communications between NAIC and stakeholders, lack of breeding policy and herd recording system, inadequate resource in terms of inputs and facilities, and absence of incentives and rewards to motivate AI technicians and the limitations of the number of AI Centers and lack of the supply of AI materials. However, now days the government has given great emphasis on sector of the livestock to increase the income of the country as a whole and improve the livelihood of the farmers' and cattle keepers. This can be noted from establishment of the AI centers across the regions and improving the animal breeding technologies in different ways. The Nekemte $\mathrm{AI}$ center is one of the newly established AI Centre which can contribute a great role in improving animal breeding policy in Oromia region and other neighboring regions in general. So this manual notes that the animal keepers and farmers found in the region and neighboring regions have got the great opportunity in increasing the income from this technology being aware of about this technology and utilizing it and great attention should be given by all concerned bodies (policy makers, researchers, practitioner, development workers, etc) about this technology and its utilizations at large.

Based on the above conclusions the following recommendations are forwarded

a) Efficient national body responsible to coordinate and monitor AI service, herd recording and also livestock breeding programs should either be reorganized;

b) Mechanisms should be devised to increase the involvement of stakeholders in the activities of AI technologies in the country. 
c) Professional associations should critically work in close collaborations with the Ministry of livestock and Fishery in formulating policies and implementation strategies;

d) Selection of bulls for AI should strictly follow the standard guidelines and procedures set for the purpose and also the national livestock development policies of the country;

e) The private sector should be encouraged to be involved in the AI service sector but with strict control by an active breeding policy;

f) The AI service provision should be restructured in such a way that it responds well to the breed improvement programs of the country.

g) New other semen and liquid nitrogen production and distribution centers should be established in order to satisfy the demand of the livestock keepers which always hinders the utilization of this technology.

h) Community awareness creation should always be available to increase the understanding of the community in order to use this technology and increase the income of the community from the livestock sector.

\section{References}

1. FAOSTAT (2011) Production statistics, Live animals, FAO Statistics Division, Rome, Italy: Food and Agriculture Organization of the United Nations (FAO).

2. MoARD (2007) Livestock development master plan study. Phase 1 repotData collection and analysis. Volume 1- Dairy. Addis Ababa, Ethiopia: GRM International BV.

3. Aklilu Y (2002) An Audit of the livestock marketing status in Kenya, Ethiopia and Sudan, Volume 1. Nairobi, Kenya: OAU-IBAR.

4. ELMP (2015) Ethiopian Livestock Master Plan. Roadmaps for Livestock Production and Transformation.

5. Lobago F (2007) Reproductive and Lactation Performance of Dairy Cattle in the Oromia Central Highlands of Ethiopia with Special Emphasis on Pregnancy Period. Doctoral thesis, Swedish University of Agricultural Science.
6. CSA (2006) Central Statistics Agency, Federal Democratic Republic of Ethiopia Agricultural Sample Survey 2006/07, volume II, Report on livestock and livestock characteristics. Statistical Bulletin 388. Addis Ababa, Ethiopia, p. 9-10.

7. Webb DW (2003) Artificial Insemination in Cattle. University of Florida, Gainesville. IFAS Extension DS 58: 1-4.

8. Bearden HJ, Fuquary JW, Willard ST (2004) Applied Animal Reproduction. (6 $6^{\text {th }}$ edn). Mississippi State University. Pearson, Prentice Hall. Upper Saddle River, New Jersey 07458. pp. 155-233.

9. Yemane B, Chernet T, Shiferaw T (1993) Improved Cattle Breeding. National Artificial Insemination Centre. Addis Ababa, Ethiopia, p. 15.

10. Zewdie E, Mussa A, Melese GM, HaileMariam D, Perera BMAO (2006) Improving artificial insemination services for dairy cattle in Ethiopia. In: Improving the reproductive management of smallholder dairy cattle and the effectiveness of artificial insemination services in Africa using an integrated approach. International Atomic Energy Agency (IAEA), p. 17-19.

11. GebreMedhin D (2005) All in one: A Practical Guide To Dairy Farming Agri-Service Ethiopia Printing Unit, Addis Ababa, p. 15-21.

12. Shiferaw Y, Tenhagen BA, Bekana M, Kasa T (2003) Reproductive performance of crossbred dairy cows in different production systems in the central highlands of Ethiopia. Trop Anim Health Prod 25: 551-561.

13. Tegegn A, Kassa T, Mukassa-Mugerwa E (1995) Aspects of bull production with emphasis on cattle in Ethiopia. П. Sperm production capacity and semen characteristics. In: Proceeding of the Third National Conference of Ethiopian Society of Animal production, p. 83-99.

14. Himanen A., Tegegn A. 1998: A Proposal for Establishment of a National Milk Recording and Herd Registration Scheme in Ethiopia. Ministry of Agriculture, Addis Ababa, Ethiopia.

15. Bekele T (2005) Calf Sex Ratios in Artificially Inseminated and Natural Mated Female Crossbred Dairy Herd. In: proceedings of the 13th annual conference of the Ethiopian Society of Animal Production. Addis Ababa Ethiopia, p. 225-230.

16. Sinishaw W (2005) Study on semen quality and field efficiency of Al bulls kept at the National Artificial Insemination Center. Debre Zeit 53(2): 135-138.

17. Dekeba A, Ayalew W, Hedge PB, Taddese Z (2006) Performance of the Abernossa Ranch in the production of Ethiopian Boran x Holstein crossbred dairy heifers in Ethiopia. Ethiopian Journal of Animal production 6(1): 33-53
This work is licensed under Creative Commons Attribution 4.0 License

Submission Link:

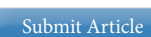

DOI: $10.32474 / C D V S .2018 .01 .000117$

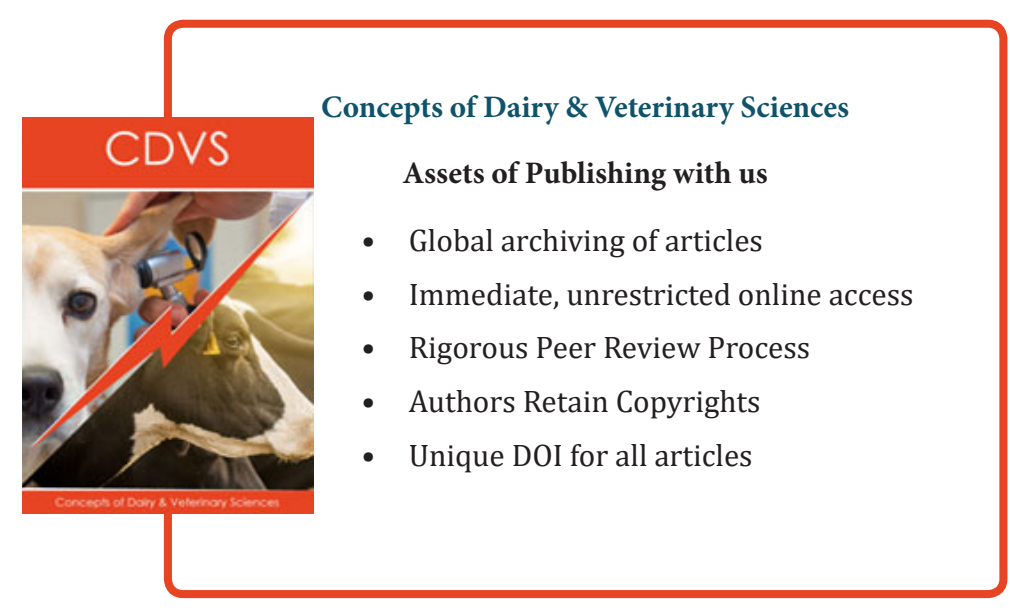

